\title{
Colorectal Cancer pTis Lamina Propria Invasion TNM Finding
}

National Cancer Institute

\section{Source}

National Cancer Institute. Colorectal Cancer pT is Lamina Propria Invasion TNM Finding. NCI Thesaurus. Code C60843.

Colorectal cancer in situ involving the lamina propria (intramucosal) without extension through the muscularis mucosa into the submucosa. (from CAP Colorectal Cancer Protocol-January 2005 Revision) 